Itinéraires Itinéraires

Littérature, textes, cultures

\title{
Sylvie Crinquand (dir.), Dernières lettres
}

\section{Kamila Ghlis}

\section{OpenEdition}

\section{Journals}

Édition électronique

URL : http://journals.openedition.org/itineraires/1311

DOI : 10.4000/itineraires. 1311

ISSN : 2427-920X

Éditeur

Pléiade

\section{Édition imprimée}

Date de publication : 1 décembre 2009

Pagination : 193-194

ISBN : 978-2-296-10791-5

ISSN : 2100-1340

Référence électronique

Kamila Ghlis, «Sylvie Crinquand (dir.), Dernières lettres », Itinéraires [En ligne], 2009-4 | 2009, mis en ligne le 03 septembre 2014, consulté le 22 septembre 2020. URL : http://journals.openedition.org/ itineraires/1311 ; DOI : https://doi.org/10.4000/itineraires.1311

Ce document a été généré automatiquement le 22 septembre 2020.

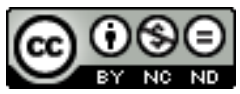

Itinéraires est mis à disposition selon les termes de la licence Creative Commons Attribution - Pas d'Utilisation Commerciale - Pas de Modification 4.0 International. 


\title{
Sylvie Crinquand (dir.), Dernières lettres
}

\author{
Kamila Ghlis
}

\section{RÉFÉRENCE}

Sylvie Crinquand (dir.), Dernières lettres, Dijon, Éditions universitaires de Dijon, coll. « Kaléidoscopes », 2008, 249 pages, ISBN : 978-2-915-55293-5

1 Reposant sur un corpus riche et varié de lettres fictives et réelles, le recueil critique et collectif intitulé Dernières lettres pose la problématique de la clôture épistolaire en tant qu'objet littéraire et acte communicationnel.

Divisé en deux parties, le volume Dernières lettres analyse tout d'abord le lien établi depuis l'Antiquité entre épistolarité et littérature. Des Héroïdes d'Ovide à Possession de A. S. Byatt en passant par Histoire d'une fauvette de Giovanni Verga, se pose la question d'une rhétorique de la dernière lettre dans les œuvres de fiction. Non seulement la lettre crée l'illusion du réel dans un texte fictionnel, mais encore le topos de l'ultime lettre participe à la structure même de l'œuvre et peut servir d'incipit ou de conclusion à un roman. Néanmoins la réflexion va au-delà du simple aspect structurel pour s'interroger sur la relation ambiguë qui existe entre fiction et écriture de soi. Les textes La Dernière Lettre d'Andreas Thamayer et La Dernière Lettre d'un homme de lettres d'Arthur Schnitzler ainsi que Laissez-moi de Marcelle Sauvageot relèvent de cette problématique : on observe l'influence autobiographique dans l'œuvre fictionnelle de Schnitzler quand Laissez-moi, pur produit de l'écriture de soi, pourrait constituer l'ébauche d'un éventuel roman.

3 La seconde partie du recueil ne traite que de lettres réelles rédigées par des hommes et des femmes célèbres ou ordinaires; elles soulignent toute la diversité et la complexité inhérentes à la clôture épistolaire. Keats mourant écrit trois lettres différentes, à la fois dans le contenu et dans le temps, et ce en fonction de ses destinataires. Ici la dernière lettre est donc protéiforme. Annette von Droste-Hülshoff, quant à elle, écrira plusieurs 
lettres avant de trouver la force de rédiger l'ultime missive à celui qu'elle aime. Ainsi les écrits de Rodin, Rainer Maria Rilke ou Virginia Woolf côtoient-ils ceux des soldats de l'an II qui, avant l'assaut final, écrivaient à leur famille sans savoir qu'il s'agissait de leur dernier message: dans ce cas, la dernière lettre s'ignore. Quels que soient les auteurs et leurs situations d'énonciation, toutes les lettres offrent à lire les vrais moments de vie que sont la rupture amoureuse, l'amitié, la maladie, le mal de vivre et la mort. À mi-chemin entre critique littéraire et analyse historique, ce recueil de Dernières lettres offre un échantillon de choix pour quiconque veut appréhender les différentes dimensions de la clôture épistolaire sous ses formes réelles ou fictives.

\section{AUTEURS}

KAMILA GHLIS

Université Paris 13 